\title{
Randomized study comparing safety and efficacy of one shot versus serial metal telescopic dilation technique in percutaneous nephrolithotomy
}

\author{
Ganesh Bhakta Acharya, Anil Shrestha, Hari Bahadur KC, Robin Bahadur Basnet, Aravind Kumar Shah, Paras
} Mani Shrestha

Department of Urology, National Academy of Medical Sciences, Kathmandu, Nepal

Correspondence: Dr. Ganesh Bhakta Acharya, Department of Urology, National Academy of Medical Sciences, Bir Hospital, Kathmandu

Email: ganeshnme@yahoo.com

\begin{tabular}{l} 
Abstract \\
\hline \hline Introduction: Dilation of the track can be achieved by multiple incremental flexible Amplatz type, \\
Alken metal telescoping dilators, or balloon in Percutaneous Nephrolithotomy(PCNL). Balloon \\
dilator is the most expensive method. Both of the incremental dilation techniques are more time \\
consuming with higher failure rates. Hence, a prospective randomized study was conducted to \\
compare the safety and efficacy of "single shot" dilation of the nephrostomy tract by amplatz dilator \\
with serial alken metallic telescopic dilation technique in PCNL. \\
Methods: Of the 138 renal stone patients who underwent PCNL from January 2015 to December \\
2015, 100 patients were randomized into two groups. Serial tract dilation with alken metallic dilators \\
was used in group A (n=50), and one shot dilation technique in Group B (n=50). The access tract \\
dilation time, success rate, blood loss and complications were evaluated. \\
Results: Both the groups were comparable in terms of mean age, location and size (largest diameter) \\
of the stone (p $>0.05$ ). No difference was observed in the procedural success rate between groups A \\
and B (96\% v $94 \%$ respectively, p=0.64). Mean access time was similar in both groups (5.89+2.67 \\
vs $4.98 \pm 2.0$ mins, p=0.06). Complications between the groups were not significantly different. There \\
were 6 patients with previous open stone surgery in both the groups. Previous open stone surgery did \\
not impact procedural success rate, access time and complications in both groups. \\
Conclusion: One-shot dilation technique is equally as effective, safe and well tolerated as metal \\
telescopic dilation techniques even in patients with history of ipsilateral open stone surgery. \\
Keywords: Amplatz dilator; One-shot dilation; Percutaneous nephrolithotomy (PCNL); Serial \\
metal telescopic dilation.
\end{tabular}

\section{Introduction}

Percutaneous nephrolithotomy is an efficient method for the management of various types of renal stone disease. The procedure is usually achieved through a percutaneous needle access to the renal collecting system under fluoroscopic guidance. This is then followed by nephrostomy tract dilation. Dilation of the tract may be achieved by many different techniques such as amplatz sequential fascial dilators, metal telescopic dilators and balloon dilators. ${ }^{1}$
Balloon dilation is regarded as the most modern and safest method with a low bleeding complication; however, its high cost precludes its routine use for every patient, especially in developing countries. Furthermore, in patients with renal scars, the application of a balloon dilator system is difficult with higher failure rates. ${ }^{2}$

Dilation with the amplatz set, which leads to the waste of 10 disposable dilators for each procedure, has intermediate cost similar to the cost of pneumatic dilation. Dilation with 
alken system is the least expensive procedure. But both of these multiple incremental dilation techniques are more time consuming and require longer exposure to fluoroscopy than balloon dilation. Furthermore, incremental dilator system such as alken and amplatz are associated with risk of working guidewire displacement, buckling and development of a false passage. The result could be hemorrhage, collecting system perforation and even operation failure. In some studies, as many as one third of patients needed blood transfusion when tract dilation was based on these methods. ${ }^{3,4}$

To reduce the risk of access complications and improve the access and radiation exposure times, various approaches have been improved. ${ }^{5,6}$ These dilation systems which comprise of single step acute dilation named "one shot" or "single shot" technique include a single dilation of the nephrostomy tract with a desired amplatz dilator. These dilation systems are rapid, single step access systems that are supposed to decrease the chance of access failure, time of operation and radiation exposure. Moreover, one shot dilation technique has been shown to be as safe and effective as metal telescopic dilation even in patients with a history of ipsilateral open renal surgery. ${ }^{7}$ However due to the lack of sufficient investigations with a large enough sample size, their application has not yet become universal.

Our aim in this study was to compare the safety and efficacy of single shot dilation of the nephrostomy tract by amplatz dilator and serial alken metallic telescopic dilation technique. We also compared the feasibility of single shot technique in patients with previous open stone surgery.

\section{Patients and Methods}

This prospective randomized study was carried out on patients who underwent PCNL for renal stone disease in Department of Urology, National Academy of Medical Sciences, Nepal from January 2015 to December 2015. The purpose of the study was explained to all the patients and their written informed consent was obtained. This study was approved by Institutional Review Board (IRB). Inclusion criteria included all patients above 18 years of age who were posted for PCNL for renal calculus disease. Patients undergoing bilateral simultaneous PCNL for the bilateral stone on the same sitting, patients with nephrostomy tube in situ and patients with more than single access tract were excluded. Admissions were done a day prior to surgery and randomized by computer generated tables into two groups; Group A: alken metallic telescopic dilators and Group B: amplatz "One Shot' technique.
The surgery was performed under regional or general anesthesia. All the surgeries were performed by experienced consultant urologist in the institution. First the patient was kept in lithotomy position and $5 \mathrm{~F}$ or $6 \mathrm{~F}$ ureteral catheter was placed in desired ureter under fluoroscopic guidance with $19 \mathrm{~F}$ cystoscope which allows the injection of contrast or saline. Thereafter, the patient was changed to the prone position. In each group the puncture of collecting system was achieved by 18-gauge needle under fluoroscopic guidance. The return of urine on removal of stylet confirmed entrance into the collecting system. A 0.035 inch straight tip hydrophilic guidewire was then inserted and skin incision of $10 \mathrm{~mm}$ was made on the puncture site. Then fascial dilation was done by $9 \mathrm{~F}$ fascial dilator. In Group A patients this step was followed by insertion of the Alken guide and of the serial telescopic dilators from $9 \mathrm{~F}$ to $27 \mathrm{~F}$. Then 24-26 F Amplatz sheath was passed and dilators were removed. In Group B a single reusable 24-26 F Amplatz dilator was advanced over an Alken guide which was followed by passage of 24-26 F Amplatz sheath and the dilator was removed.

Demographic data as well as intraoperative information such as access time (the time elapsed between insertion of guide wire after puncture into the collecting system and the placement of Amplatz sheath) and success rate (complete dilation to desired caliber and successful nephroscope entrance into collecting system) were recorded. Once the stone was localized pneumatic lithotripsy was performed for stone fragmentation. Patient requiring more than one tract for clearance of stone was excluded from the study.

Postoperative hemoglobin concentration and hematocrit level were measured four and 24 hours after the surgery. The rate of hemoglobin drop was compared with the preoperative hemoglobin level. Presence of fever/sepsis as well as number of blood transfusion or need of angioembolisation were also recorded. Complications were also noted.

Patients were followed up after one week to look for any features of delayed hemorrhage or urinary leak from the percutaneous site.

Finally, presence of complication after PCNL were graded as Modified Clavien-Dindo Classification. ${ }^{8}$

Statistical analysis was performed using chi-square, student's t-test and $\mathrm{z}$ test. The level of significance was defined as $p<0.05$. All data were analyzed with SPSS version 17 software (Chicago, IL). 


\section{Results}

Out of 138 patients of renal stone enrolled in the study, 38 patients were excluded due to multiple tract. Remaining 100 hundred patients, 50 in each group, were finally analyzed. These groups were similar in terms of age and sex, and there were no significant differences in preoperative variables such as mean stone size, location and side (Table 1).

\section{Table 1. Preoperative variables of patients}

$\begin{array}{llll}\text { Parameters } & \text { Group A(n=50) } & \text { Group B(n=50) } & \text { p-Value } \\ \text { Mean Age (years)(range) } & 38.7(20-72) & 39.5(18-75) & 0.587 \\ \text { Male/female } & 32 / 18(64 \% / 36 \%) & 36 / 14(72 \% / 28 \%) & 0.389 \\ \text { Side(R/L) } & 20 / 30(60 \% / 40 \%) & 21 / 29 & 0.979 \\ \text { History of ipsilateral open } & 6(12 \%) & (58 \% / 42 \%) & 1.00 \\ \text { stone surgery } & & 6(12 \%) & \\ \text { Stone location } & 24 & 27 & \\ \text { Renal pelvis } & 9 & 8 & \\ \text { Staghorn } & 11 & 11 & \\ \text { Lower calyx } & 4 & 3 & \\ \text { Middle calyx } & 2 & 1 & \\ \quad \text { Upper calyx } & 20+11 & 19 \pm 7\end{array}$

Group A, alken serial dilation; Group B, single shot dilation

The mean access time(mins) was shorter in group B than group A (5.89 vs 4.98) but not statistically significant( $\mathrm{p}=0.061)$. Success rate was similar in both the groups $(96 \%$ vs $94 \%$; $=0.64)$. Dilation related intraoperative complications were higher in group A ( $26 \%$ vs $14 \% ; p=0.13)$ but not significantly different (Table 2).

\section{Table 2. Intraoperative variables}

$\begin{array}{llcc}\text { Parameters } & \text { Group A }(\mathbf{n = 5 0}) & \text { Group B (n=50) } & \text { p-value } \\ \text { Entrance calyx } & 23(46 \%) & 19(38 \%) & 0.211 \\ \text { Lower } & 19(38 \%) & 27(54 \%) & \\ \text { Middle } & 8(16 \%) & 4(8 \%) & \\ & 5.89 \pm 2.67 & 4.98 \pm 2.0 & 0.061 \\ \text { Upper } & 48(96 \%) & 47(94 \%) & 0.64 \\ \text { Mean access time(min) } & 6(12 \%) & 2(4 \%) & 0.14 \\ \text { Success rate } & 5(10 \%) & 4(8 \%) & 0.72 \\ \text { Under dilation } & 2(4 \%) & 1(2 \%) & 0.55 \\ \text { Over dilation } & & & \end{array}$


Group A, alken serial dilation; Group B, single shot dilation Under dilation, amplatz sheath within the kidney but not in the desired calyx; Over dilation, amplatz sheath beyond the desired calyx but still inside the kidney; Collecting system perforation, amplatz sheath passed beyond the calyx and outside of the kidney

Table 3. Postoperative values and outcome of procedure

\begin{tabular}{|c|c|c|c|}
\hline Parameters & Group A $(\mathrm{n}=\mathbf{5 0})$ & Group B $(n=50)$ & p-value \\
\hline \multicolumn{4}{|l|}{ Mean postoperative $\mathrm{Hb}$ drop $(\mathrm{g} / \mathrm{dl})$} \\
\hline & \multicolumn{3}{|l|}{$1.27 \pm 1.10$} \\
\hline After 4 hrs. & \multirow[b]{2}{*}{$1.46 \pm 1.32$} & $1.71 \pm 1.41$ & 0.086 \\
\hline After 24 hrs. & & $1.74 \pm 1.35$ & 0.30 \\
\hline Blood transfusion $(\%)$ & $1(2 \%)$ & $4(8 \%)$ & 0.16 \\
\hline Hydrothorax (\%) & $1(2 \%)$ & $1(2 \%)$ & 1.0 \\
\hline Urinary leak (\%) & $1(2 \%)$ & $1(2 \%)$ & 1.0 \\
\hline Postoperative urinary tract & $9(18 \%)$ & $7(14 \%)$ & 0.58 \\
\hline infection (\%) & & & \\
\hline Mean hospital stays + SD(days) & $3.30 \pm 1.61$ & $3.24 \pm 1.27$ & 0.837 \\
\hline
\end{tabular}

Group A, alken serial dilation; Group B, single shot dilation; Hb, Hemoglobin

Mean hemoglobin drop in both the group were not significantly different. Five patients received blood transfusion in the postoperative period ( 1 in group A and 4 in group B). (Table 3 ) There were three patients in group A and four patients in group B who were readmitted after discharge for hematuria and all of them recovered well with conservative management. None of the readmissions required blood transfusion. Postoperative UTI ( 9 patients in group A and 7 patients in group B), postoperative hydrothorax (1 patient in each group) was managed by antibiotics and pleural tapping respectively. Two patients developed urinary leak (one patient in each group), which were managed by DJ stenting and Foley catheterization. There was no visceral or vascular injury in either of the group. Residual stones were present in 14 patients (11 in group A and 3 in group B) and ancillary procedures, such as shock wave lithotripsy or re-PCNL were performed. Hospital stay was similar in both the groups $(3.30 \pm 1.61$ vs $3.24 \pm 1.27$ days; $p=0.837)$. No significant difference in complications between the two groups (Table 4) was noted.

Table 4. Complications as per Modified Clavien Dindo Classification

$\begin{array}{llll}\text { Parameters } & \text { Group A }(\mathbf{n}=\mathbf{5 0}) & \text { Group B }(\mathbf{n}=\mathbf{5 0}) & \text { p-value } \\ \text { Grade } & & & 0.164 \\ \text { None } & 21(42 \%) & 12(24 \%) & \\ 1 & 20(40 \%) & 22(44 \%) \\ 2 & 6(12 \%) & 8(16 \%) \\ 3 \mathrm{~A} & 3(6 \%) & 8(16 \%) \\ 3 \mathrm{~B} & - & - \\ 4 & - & - \\ 5 & - & -\end{array}$

Group A, alken serial dilation; Group B, single shot dilation 
Six patients in each group had history of previous renal surgery but none of them failed the dilation technique. Two patients had over dilation in group B which was not statistically significant. Overall complications and surgical outcome was not significantly different between these subgroups.

\section{Discussion}

PCNL is the gold standard treatment for the management of large renal stones $(>2 \mathrm{~cm})$ that has revolutionized surgical treatment, with minimally invasive procedures now being preferred over open surgical approaches. The creation and dilation of nephrostomy tract is the key step of PCNL, which is performed basically with three dilation methods; metal telescopic Alken dilators, incremental Amplatz dilators or balloon dilators. All of these techniques help in creating the nephrostomy tract over which an Amplatz sheath of desirable size(28-34 F) can be passed. ${ }^{2,9}$ Balloon dilator is considered the most safe method for one step tract dilation; however its high cost precludes its use in many centers with limited resourses. ${ }^{2,10}$ Besides it has got higher failure rate in patients with previous renal scars. ${ }^{2}$ Amplatz dilator and/or metal Alken dilator system is the second best option where balloon dilator system is not feasible or available for tract creation; however, their incremental nature can be a problem especially in terms of prolongation of access time, radiation exposure and possibility of tract displacement.

To improve the dilation results, some authors have proposed single-increment dilation and demonstrated its safety and feasibility. ${ }^{11,12}$ They performed this technique in dogs to investigate the effects of single-increment renal tract dilation to $24 \mathrm{~F}$ and compared with conventional techniques. ${ }^{12}$ The effects of this technique was compared with those of multi-incremental or balloon dilation and found no difference in tissue damage either immediately or at 6 weeks. However, it was demonstrated that although the one stage tract dilation technique reduced radiation exposure and access time in the short term, it may cause more parenchymal damage than the gradual dilation technique. ${ }^{13}$

They described a dilator composed of an $8 \mathrm{~F}$ polyurethane tube cemented to a gradually tapering polyurethane dilator of the desired size (10F to $34 \mathrm{~F}$ ) that was passed over a guidewire into the pyelocaliceal system, with the $8 \mathrm{~F}$ portion entering the proximal part of the ureter. ${ }^{11}$ Whilst other described a single dilation with a $25 \mathrm{~F}$ or $30 \mathrm{~F}$ Amplatz dilator advanced over an Alken guide or an $8 \mathrm{~F}$ dilator. ${ }^{5}$ The results were comparable with current standard techniques and fluoroscopy time and cost were significantly reduced.
Our technique was performed using available reusable instruments and it was not based on passing the port of the dilator into the ureter thus being feasible even in the presence of stones that completely occlude the calyx, preventing the passage of any instrument into the renal pelvis. We compared one- shot technique with conventional metal telescopic dilators. Our results clearly show that the one-shot procedure is feasible and effective.

Open Nephrolithotomy leads to retroperitoneal scars around the kidney that may adversely affect introduction of access needle and prevent proper dilation of the tract, necessitating the use of metal and balloon dilators. ${ }^{14,15}$ Previous studies reported a higher failure rate for PCNL in those patients with previous open intervention. ${ }^{14,}{ }^{16}$ It has been reported that one shot dilation was unsuccessful in two patients who had history of previous open stone surgery. ${ }^{5}$ Similarly, in other study one-shot dilation was unsuccessful in three patients, out of which two had history of previous open renal surgery. ${ }^{7}$ They noted that these features represented real contraindication to oneshot technique. Kidney with previous open surgery can be punctured easily by the access needle using amplatz dilators for tract dilation without any technical difficulties. ${ }^{17}$ Three $(6 \%)$ of our cases of one-shot technique were unsuccessful. The causes in these patients were, guidewire displacement during the process of dilation, tract lost and under dilation. None of the patients had history of previous renal surgery. In our study, there were six patients in group B who had history of ipsilateral stone surgery but none of them had failed one-shot technique.

Mean access time, success rate, perioperative complications, mean hemoglobin drop were not significantly different in both the groups with history of previous open stone surgery which demonstrates that one shot technique is equally effective and safe in patients with history of open stone surgery. Similarly, one shot procedure has been seen to be feasible in patients with previous open nephrolithotomy. ${ }^{18}$ It was safe and effective as the telescopic procedure, with significant reduction in X-ray exposure.

Single shot dilation is safe and effective in almost every adult population. ${ }^{70,19,20}$ One shot dilation did not lead to more hemorrhagic complications than alken serial dilation techniques. In our study, four $(8 \%)$ patients required blood transfusion, which is comparable with other results. ${ }^{5,7}$ None of the patients required conversion to open surgery or angioembolisation. Complications were graded in terms of Modified Clavien-Dindo classification in both the groups, and results were not significantly different. 


\section{References}

1. Alken P, Hutschenreiter G, Gunther R, Marberger M. Percutaneous stone manipulation. J Urol 1981; 125:463-467. https://doi.org/10.1016/S00225347(17)55073-9.

2. Davidoff R, Bellman GC. Influence of technique of percutaneous tract creation on incidence of renal hemorrhage. J Urol 1997; 157:1229-1231. https://doi. org/10.1016/S0022-5347(01)64931-0.

3. Kessaris DN, Bellman GC, Pardalidis NP, Smith AG. Management of hemorrhage after percutaneous renal surgery. J Urol 1995; 153:604-608. https://doi. org/10.1016/S0022-5347(01)67659-6.

4. Roth RA, Beckmann CF. Complications of extracorporeal shockwave lithotripsy and percutaneous nephrolithotomy. Urol Clin North Am 1988; 15:155-1566. PMid:3289226.

5. 5. Frattini A, Barbieri A, Salsi P, Sebastio N, Ferretti S, Bergamaschi E, Cortellini P. One shot: A novel method to dilate the nephrostomy access for percutaneous lithotripsy. J Endourol 2001; 15:919-923. https://doi org/10.1089/089277901753284143; PMid:11769847.

6. McDougall EM, Liatsikos EN, Dinlenc CZ, Smith AD. Percutaneous approaches to the upper urinary tract. In: Walsh PC, Vaughan ED, Wein AJ, Retik AB, eds. Campbell's Urology. 8th ed. Philadelphia: WB Saunders, 2002, pp 3320-3369.

7. Siavash Falahatkar, M.D., Hassan Neiroomand, M.D., Marzieh Akbarpour, M.D., Seyedeh Atefeh Emadi, M.D., and Negin Khaki, M.D. One-Shot Versus Metal Telescopic Dilation Technique for Tract Creation in Percutaneous Nephrolithotomy: Comparison of Safety and Efficacy. Journal Endourol April 2009; 23(4):615-618. https://doi.org/10.1089/end.2008.0330; PMid:19335153.

8. Jean J.M.C.H. de la Rosette, Dedan Opondo, Francisco P.J. Daels, Guido Giusti, A'lvaro Serrano, Sangam V. Kandasami, J. Stuart Wolf Jr., Magnus Grabe, Stavros Gravas. Categorization ofComplications and Validation of the Clavien Score for Percutaneous Nephrolithotomy. European Association of Urol 2012; 62:246-255. https://doi.org/10.1016/j.eururo.2012.03.055; PMid:22487016.
9. Gupta M, Ost MC, Shah JB, et al. Percutaneous management of the upper urinary tract. In: Wein AJ, Kavoussi LR, Novick AC, Partin AW, Peters CA, eds. Campbell-Walsh Urology. 9th ed. Philadelphia: Saunders Elsevier, 2007, pp 1526-1563.

10. Ziaee SA, Karami H, Aminsharifi A, et al. One-stage tract dilation for percutaneous nephrolithotomy: Is it justified? J Endourol 2007; 21:1415-1420. https://doi.org/10.1089/end.2006.0454; PMid:18186676.

11. . Rusnak B, Castaneda-Zuniga W, Kotula F, Herrera M, AmplatzK.Animproved dilatorsystem forpercutaneous nephrostomies. Radiology 1982 July; 144(1):174. https://doi.org/10.1148/radiology.144.1.7089252; PMid:7089252

12. Travis DG, Tan HL, Webb DR. Single-increment dilatation for percutaneous renal surgery: an experimental study. Br J Urol.1991; 68:144-147. https://doi.org/10.1111/j.1464-410X.1991.tb15282.x; PMid:1884139.

13. Alireza Aminsharifi, Mehrosadat Alavi, Ghasem Sadeghi, Saeed Shakeri, and Firoozeh Afsar. Renal Parenchymal Damage after Percutaneous Nephrolithotomy with One-Stage Tract Dilation Technique: A Randomized Clinical Trial. Journal of Endourology 2011 June; 25(6):927-931.https://doi. org/10.1089/end.2010.0638; PMid:21542774.

14. Vivile C. Percutaneous nephrolithotomy: Personal experience in 100 cases. J Urol (Paris) 1987; 93:253258.

15. Margel D, Lifshitz DA, Kugel V, Dorfmann D, Lask D, Livne PM. Percutaneous nephrolithotomy in patients who previously underwent open nephrolithotomy. J Endourol 2005; 19:1161-1164. https://doi. org/10.1089/end.2005.19.1161; PMid:16359205.

16. Jones DJ, Russell GL, Kellett MJ, Wickham JE. The changing practice of percutaneous stone surgery: Review of 100 cases 1981-1988. Br JUrol 1990; 66:1-5. https://doi.org/10.1111/j.1464-410X.1990.tb14852.x; PMid:2393785.

17. Sofikerim M, Demirci D, Gu* lmez I, Mustafa K. Does previous open nephrolithotomy affect the outcome of percutaneous nephrolithotomy? J Endourol 2007; 21:401-403. https://doi.org/10.1089/end.2006.0293; PMid:17451330. 
18. Amjadi M, Zolfaghari A, Elahian A, Tavoosi A. Percutaneous nephrolithotomy in patients with previous open nephrolithotomy: One-shot versus telescopic technique for tract dilatation. J Endourol 2008; 22:423-426. https://doi.org/10.1089/ end.2007.0206; PMid:18271716.

19. mirhassani S, Mousavi-Bahar SH, Iloon Kashkouli A, Torabian S. Comparison of the safety and efficacy of one-shot and telescopic metal dilatation in percutaneous nephrolithotomy: a randomized controlled trial. Urolithiasis 2014 Jun; 42(3):269-273. https://doi.org/10.1007/s00240-014-0644-5; PMid:24531816.

20. Dehong C, Liangren L, Huawei L, Qiang W. A comparison among four tract dilation methods of percutaneous nephrolithotomy: a systematic review and meta-analysis. Urolithiasis 2013 Nov; 41(6):523530. https://doi.org/10.1007/s00240-013-0598-z; PMid:23975408. 